\title{
The potential of agroforestry as an adaptation strategy to mitigate the impacts of climate change: A case study of Kiine Community, Kenya
}

\author{
MUNENE ANNE NYARUAI, JOHN K. MUSINGI", BONIFACE N. WAMBUA \\ Department of Geography and Environmental Studies, University of Nairobi. Nairobi, Kenya. "email: jmusingi@uonbi.ac.ke, \\ wambua_boniface@uonbi.ac.ke
}

Manuscript received: 5 April 2018. Revision accepted: 16 August 2018.

\begin{abstract}
Nyaruai MA, Musingi JK, Wambua BN. 2018. The potential of agroforestry as an adaptation strategy to mitigate the impacts of climate change: A case study of Kiine Community, Kenya. Nusantara Bioscience 10: 170-177. This study has a purpose of evaluating the agroforestry potent as a conformation policy to the effects of climate change in the location of the study. One hundred farmers were used as study sample in collecting data with stratified sampling technique. To achieve data from individual farmers, both arranged and disarranged questionnaires were used. The study utilized questionnaires and observation timetable to collect data from individual farmers associated with the study objectives. The study found out that more preferable practices in agroforestry were planting the trees and shrubs as windbreakers, riparian forest buffers, silvopasture, and boundary planting while the less preferable practices were forest farming, alley cropping, and woodlots. It also found that the coaching to identify both indigenous and exotic agroforestry tree species is needed. In particular, $94 \%$ and $90 \%$ of the respondents got a feeling that the coaching on agroforestry practices and incorporation of exotic species is needed very much. The reason is that the feeling felt by respondents could give contribution to shortening the prolonged production time of trees on farm. On the contrary, $90 \%$ of the respondents are confident that agroforestry can increase catchment yield in rivers and streams, ameliorate the micro-climate, increase wood production as well as increase livestock health and products. The result showed that agroforestry has a direct link in increasing subsistence of people in the study area. Food (fruits), fodder, fuelwood, medicinal substances, gums, tannins, essential oils, fibers and waxes are the examples of agroforestry products sold by the surrounding farmers. The money will be used to provide second-tier facilities such as paying the tuition for their children or even getting healthcare facilities. The result shows that agroforestry is a method in agricultural production which can decrease the effects of human activities and climate change on the local environment. Agroforestry can increase the endurance of agricultural outturn to contemporary climate variance as well as prolonged climate change by means of the utilization of trees for intensification, diversification and supporting of farming systems.
\end{abstract}

Keywords: Conformation policy, agroforestry, climate change, Kenya

\section{INTRODUCTION}

The World Summit on Social Development (UN 1995) describes poverty as a "condition characterized by severe deprivation of basic human needs, including food, drinking water, sanitation facilities, health, shelter, education, and information. It depends not only on income but also on access to services". To worsen the circumstance is the poor's lineal conviction on the surrounding and its services for their subsistence.

Poverty brings to release of environmental goods at the prices which are frequently higher than equipment prices. The consequence is a degraded surrounding which cannot fulfill the requirements of the present population and also will threaten the availability of mankind's requirements in the future. Heretofore, extensive destitution and environmental degradation keeps on to be examined in spite of attempts performed by governments, nongovernmental organizations or even civil societies. Frequently contrived by deficient protection, malnourishment, elevating numbers of infant mortality, deficiency of earnings as well as unhealthy condition of life, this situation keeps on burdening developmental attempts plotted at various objectives involving to decrease destitution and/or to eliminate famine. Diverse researches have shown the relation of poverty to the environment such as those conducted by Agarwal (1997), Cleaver (1997), and UNDP (2000).

Substantially, in the 'poor' population, the surrounding in that locality is often more downgraded. Such downgrade is caused by varied activities involving populace accretion as well as technological improvement. Such activities provide a significant difference between the needs and their fulfillment in services such as energy, food, housing, transport, water, sewerage facilities, etc. Unquestionably, the consequence has been the unwanted alterations in land utilization such as deforestation, substandard farming techniques, decadence of air and water grade, instable generation and rubbish management, and rapid elevation of poverty-stricken city. The following are some of the accurate effects of environmental downgrade, (i) Widespread effects to climate change particularly on the countries in developing phase (DFID, EC, UNDP and World Bank 2002). (ii) Elevation in the establishment and the expansion of vector-borne illness including malaria (WRI 1998). (iii) Appearance of acute respiratory infections in women who frequently use fuelwood in cooking (Ezzati and Kammen 2001). (iv) Crucial 
decrement in subsistence alternatives as most of the favors provided by the environment will be remarkably decreased (Brocklesby and Hinshelwood 2001). It is undeniable to express that the above circumstances will be worsened by climate change considering the average global temperature has risen by 0.3-0.6C over the past Century (IPCC 1990). The risen temperature is contributed to greenhouse gases which are mainly resulted from human activities such as fossil fuel combusting, deforestation and substandard agricultural practices. Annually, about 13 million $\mathrm{Ha}$ of forest has been turned into land for agricultural activities (FAO 2006). The surface temperature increases to about $30^{\circ} \mathrm{C}$ due to the availability of greenhouse which traps heat released from the earth's surface (Pearce 2003) and Pierrehumbert (2004)). Tremendously brought about by pollution, the effects of climate change varied in various countries, regions, and continents (IPCC 2007).

ICRAF (2013) clarifies agroforestry as an agricultural method that unifies plants, bushes, and animals on a farm resulting in various advantages. These advantages are multiple such as the providing of food for animals and timber for fuelwood, the soil enrichment as well as the medicinal products (Sanches 2000; Kwesiga et al. 2003). Various types of Agroforestry methods are found worldwide, such as forest farming, riparian buffers, alley cropping, silvopasture, as well as forest. According to Agroforestry Research Trust (2010), various researches have delivered the advantage of integrated farming methods in comparison to monoculture method since they intensify the variety in localities of food production and the subsistence mainly through the selling of farming products. Agroforestry is a promising agricultural system in resolving many challenges of our time. The same thing occurs in Kirinyaga County. Based on Kirinyaga County First County Integrated Development Plan for 2013-2017, the main causes of environmental downgrade in the County are deforestation, substandard solid waste processing, river bank cultivation, and pollution from industries and farmers. Furthermore, this report reveals that these causes have brought to immense climate variability and change influencing the agricultural and health fields due to, among other things, uncertain rainfall schemes, recession of the glaciers on Mt Kenya which could be assumed as water tower for this county.

The country keeps on experiencing the elevating bad consequences of climate change and their effects. It gets worsened by the nowadays environmental circumstances (undervalued soils, substandard agricultural methods) as well as destitution. Hence, this study tries to clearly specify the potent of agroforestry as an adaptive action plans to the negative impact of climate change in the research area.

The purposes of this study were (i) to examine the most appropriate agroforestry practices giving maximum advantages with regard to conformation to effects of climate change in the research area, (ii) to recognize main agroforestry expenses and advantages in conformation to climate change, (iii) to decide whether agroforestry can remarkably assist the enhancements of subsistence of the community in the research area.

\section{MATERIALS AND METHODS}

\section{Scope of the research}

This study was performed in Kiine, a sub-location in Kirinyaga county, Kenya (Figure 1). In accordance with the 2009 Kenya Population and Housing Census report (KPHC 2009), the population of the county is "528,054 and has an annual growth rate of $1.5 \%$ and projected to be 595,379 in 2017, as compared to 552,359 recorded in 2012". The density of population of this County was 488 people per $\mathrm{km}^{2}$ in 2012 and hoped to be elevated higher to 524 people per $\mathrm{km}^{2}$ in 2017. The Kenya Integrated Household Budget Survey (KIHBS 2005/2006) has it that $67 \%$ of land parcels in the county have title deeds, while $23 \%$ of farmers farm on land owned by the National Irrigation Board. Furthermore, the County has a destitution rate of $36 \%$ compared with national average of $46 \%$.

The Kirinyaga County Transition Implementation Plan (KCTIP 2014) records that Kirinyaga County pervades a region of 1,478.1 square kilometers and is categorized into three ecological zones; the lowland areas that embrace 1,158-2,000 $\mathrm{m}$ asl., the midland areas laying 2,000-3,400 m asl. and the highland embracing areas of 3,400 metres to 5,380 metres above sea level. The lowland area is described by gentle rolling plains that cover most of Mwea constituency. The midland area comprises of Ndia, Gichugu and Kirinyaga Central constituencies. The highland area pervades the upper areas of Ndia, Gichugu and Central constituencies and the whole of the mountain area. Kiine belongs to Ndia constituency in Kirinyaga County. Despite its location in the midlands, this area was selected, since it has experienced the negative effects of climate change combined with the reality that about $87 \%$ of its people are hired in the agricultural sector and puts up $72 \%$ of household earnings. Farmers in the study area supplied the required data used for examining the purposes of this research.

\section{Research design}

The research utilized a descriptive survey design to collect data for analysis. Kombo and Tromp (2006) clarified that a descriptive survey as a method which primary purpose is to gather and analyze data to develop particular details. This method was more applicable, since it was efficient in data collection especially in wide area of research. Moreover, the design was used because the method does no compromise on the population under study (Kothari 2004).

\section{Target population}

The research concentrated on a sample size of 100 farmers in Kiine. The sample size was excellent and a reasonable representation of the farmer populace. Also, the sample size was excellent because of the time span and the financial plans obtainable for the research. The primary center of attraction is on Karima region, which has around 450 farmers. 


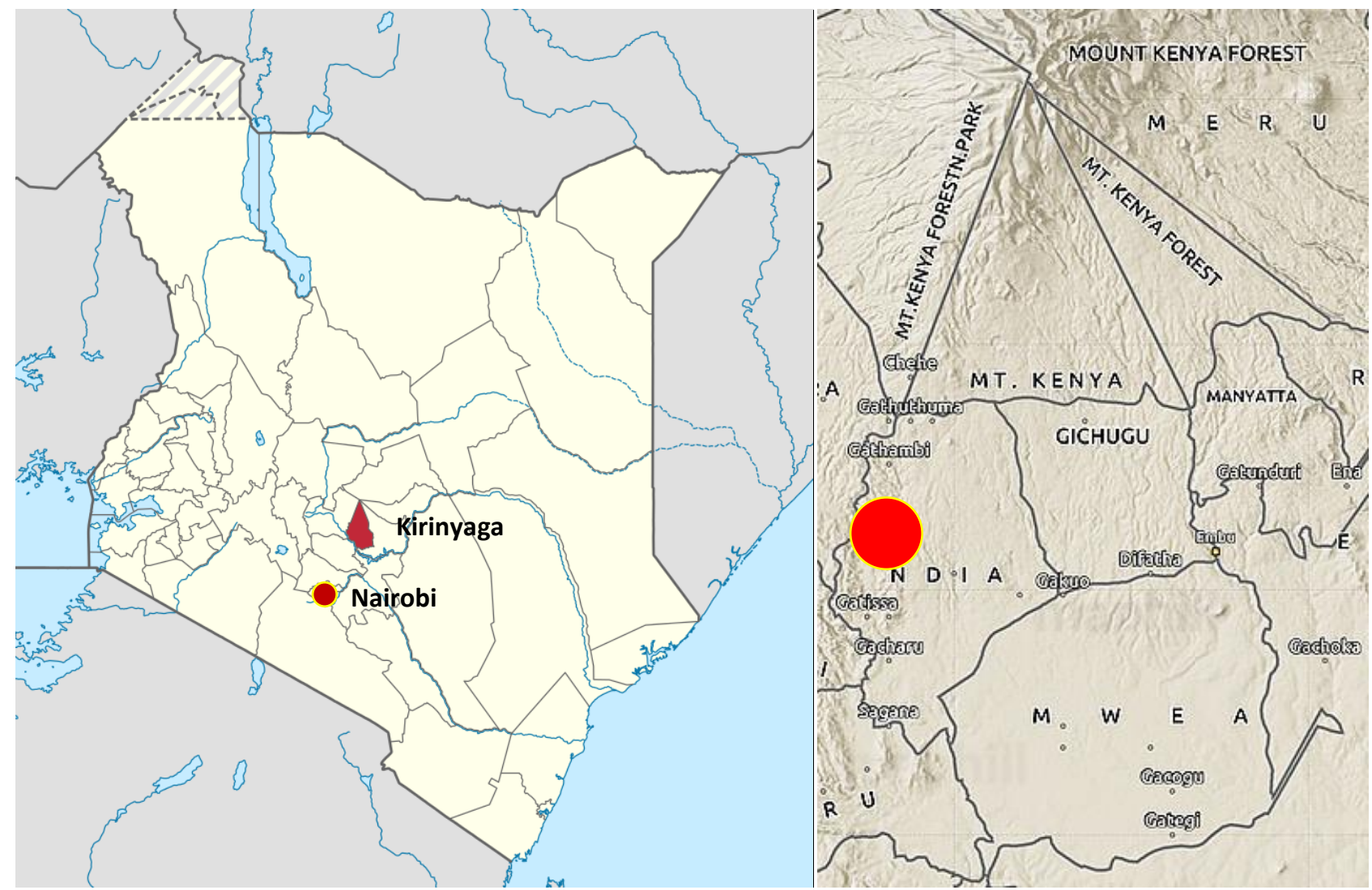

Figure 1. Location of Kiine Community ( $)$ in the Kirinyaga County, Kenya

\section{Sampling procedure and sample size \\ Sample size}

The research concentrated on a sample size of 100 farmers in Kiine. The sample size was excellent because of the time span and the financial plans obtainable for the research.

\section{Selection of study sample}

This research utilized stratified sampling technique to pick out farmers to be sampled. Stratified sampling technique principally categorizes a certain population based on described characteristics which are then utilized to acquire samples (Cochran 1963). This technique confirms equitable deputation of sub-groups in the chosen samples.

\section{Methods of data collection}

To simplify details collection in answering to the research inquiries, the research utilized three types of equipment namely questionnaires, interviews and observation. Before doing data collection from the respondents, the researcher acquired a research approval from the chief and other regional authorities. This solemn approval gave assistance to the researcher in socializing with the farmers in an effort to obtain replies that will give assistance in achieving the research objectives. The researcher then came to see the settlements in which the research would be performed to introduce herself as well as to create affinity with the respondents.

\section{Questionnaires}

The written questionary was characterized by both overt and closed-ended inquiries and was separated into five sections. The questionnaires were brought to the respondents and were collected one week later after replies had been given. The technique was preferable because it permitted the respondents sufficient time to answer the questionnaires. The utilization of questionnaires was beneficial for the study as it is easier to manage as well as to analyze the data supplied by the respondents.

\section{Interviews}

An interview was performed on illiterate respondents or on respondents who gave incomplete response to the questionnaires due to the lack of time. Hence, the research assistant would meet those respondents and would renew the questionnaires based on the feedback provided. This technique was highly beneficial for respondents who had inability in writing or reading for one reason or another.

\section{Observation}

Further examination schedules were applied to accomplish response resulted from the questionnaires, based on the feedback. For this technique, the natural settings of the study area were examined by the research assistants and responses against the set items captured in the interview schedule sheet were provided by them. 


\section{Instrument validity}

Mugenda and Mugenda (2003) elucidate that validity as the righteousness of outcomes. Validity was assured by the consultation with research experts who are supervisors to make sure that the instruments of data collection can perform their measurement correctly.

\section{Instrument reliability}

The ability of a research instrument to present fixed results upon several trials is called reliability. The reliability of the questionnaires was verified through testretest method, namely, the same questionnaires to fill were given to the same respondents two times in an in-between period of two weeks. The instruments were applied on a few selected subjects.

\section{Data analysis}

The collected data were examined with a method of descriptive statistics. The analysis process demanded an appraisal of the data captured in the questionnaires and observation timetables and detecting any inaccuracies and finally coding the responses in a manner that would assist in further analysis. The analysis conveyed the findings in terms of percentages and frequencies of occurrence utilizing the Statistical Package of Social Sciences (SPSS).

\section{RESULTS AND DISCUSSION}

\section{Response rate}

The sample population consisted of 100 farmers in Kiine, Kirinyaga County. 10 out of 100 farmers gave back unfilled questionnaires, thus response rate was $90 \%$. This high number of participants increases the findings as these would be discerned as more than sufficient representative of the population under study.

\section{Demographic profile of the respondents}

This item looked for the farmers' gender, age, level of education and the length of time they have been practicing farming. This was significant since, on a study about a particular population, certain facts must be understood first. The demographic profile of the respondents will show the way they fulfill the research appliance. The outcomes are as described below.

\section{Farmers gender}

The farmers were questioned to inform their gender and the outcomes are assumed up in Table 1. As described in Table 1, most farmers $(66.7 \%)$ were male and some $(33.3 \%)$ were female. This could be accredited to land tenancy and demesne issues which in many African regions belong to men.

\section{Age of the farmers}

The respondents were questioned to inform their age. Table 2 shows the age of the farmers who were the samples in the study area. As shown, none of the farmers were under the age of 20 years, $11.11 \%$ were between $21-30$ years old, and $16.67 \%$ were between the ages of $31-40$ years, $50 \%$ were between the ages of 41-50 years, while the remaining $22.22 \%$ were above 50 years old. This indicates that the larger part of the farmers $(50 \%)$ are between the age of 41-50.

It is significant that the middle age group in the context of the respondents (41-50) developed the bulk of agroforestry practitioners who would become the main actor in setting up competence in agroforestry practices and whom would remarkably affect its uptake. The age range 41-50 years posed the larger part of respondents (50\%), and has remarkable level of education, a factor that would escalate the favorable outcome of new agroforestry inventions to be introduced in the area.

\section{Level of education of farmers}

The respondents were questioned to inform their level of education. $11.11 \%$ were illiterate, $11.11 \%$ had owned primary level of education, 50\% had achieved secondary level of education, 27.78 had reached tertiary level of education. Table 3 shows the level of education

\section{The number of years that farmers have spent in Kiine area}

The majority $(38.89 \%)$ of interviewed farmers had lived for $10-19$ years in the village while a few $(5.55 \%)$ had lived for 50 and 59 years in the village (Table 4$)$.

\section{The climate of Kiine area}

The respondents were questioned to inform the climate of their area. $5.56 \%$ said that climate is dry and hot, $22.22 \%$ said that the climate is cool and wet, $44.44 \%$ said that the climate is cool and dry, while the remaining $27.78 \%$ said that the climate has been wet and hot. This represents that the climate of Kiine area in Kirinyaga County is cool and dry as the majority (44.41\%) stated the climate as cool and dry (Figure 2). 60\% of the population consider that climate is not the same as the climate lately, while the remaining $40 \%$ think that climate is always the same as it is today (Table 5).

Table 1. Distribution of farmers by gender

\begin{tabular}{lcc}
\hline Gender & Frequency & Percentage \\
\hline Male & 60 & 66.7 \\
Female & 30 & 33.3 \\
Total & 90 & 100 \\
\hline
\end{tabular}

Table 2. Ages of the respondents

\begin{tabular}{|l|c|c|}
\hline Age group & No. of farmers & Percentage \\
\hline below 20 & 0 & 0 \\
\hline $21-30$ & 10 & 11.11 \\
\hline $31-40$ & 15 & 16.67 \\
\hline $41-50$ & 45 & 50 \\
\hline over 50 & 20 & 22.22 \\
\hline Total & 90 & 100 \\
\hline
\end{tabular}


This shows that the climate has undergone changes over the years due to human activities having a negative impact on the environment. Regarding the impacts of climate change in their region, $65 \%$ stated that the impact was very serious, $25 \%$ said the impact was serious while the remaining $10 \%$ informed that climate change was not serious. This finding implies that the impact of climate change in the Kiine region is a serious problem (Figure 3 ).

The majority $(80 \%)$ had a feeling that the local microclimate can be made better. The remaining $20 \%$ had the feeling that it cannot be fixed. Those who feel that it can be enhanced proposed some methods such as environmental conservation, afforestation, the use of cheaper energy in agroforestry, and the punishment for environmental polluters.

\section{Investigation of agroforestry practices which provide maximum benefits in terms of adaptation of climate change impacts in the study area}

To test the preferred agroforestry technology, a fivepoint Likert scale is used and added by the range from strongly agree, agree, unsure, disagree and strongly disagree, explaining that 1 is the most preferred while 5 is the least preferred. They were then questioned to evaluate various agroforestry technologies in their village. Table 6 presents how farmers evaluate several agroforestry practices. It shows that most farmers like the placement of trees and shrubs that are very high as windbreaks, and the planting of riparian forest buffers as trees, shrubs or grasses and tree combinations with livestock. This is very different from Silvopasture which is a combination of plants with foliage and livestock on the same land, the planting shortrotation wood (woodlots) in humid areas and the Alley planting-rows of trees with a very broad space that creates alleyway of plants on the side of the hill that receives the smallest ranking.

Table 6 shows clearly that the most preferred agroforestry practices are the planting of trees and shrubs as windbreaks, planting buffer for forests reparation, silvo grazing, boundary planting, home gardening and a combination of trees with food crops. On the contrary, the most unpopular agroforestry practices are forest agriculture, alley planting and planting of woodlots in humid areas.

\section{Major agroforestry costs and benefits in adaptation to climate change \\ Agroforestry costs}

The respondents were inquired to evaluate agroforestry expenses that they could associate to on a five-point scale. The expense in this occurrence points to find that was needed to allow the respondents adopting agroforestry practices and should not be apprehended in monetary equivalent. First, the respondents were inquired if the coaching of residents on agroforestry should be intensified. From those being inquired, $44.4 \%$ strongly agreed that such coaching should be intensified, $33.33 \%$ agreed, 5.56 were not sure whether such coaching should be intensified.
Table 3. Level of education of farmers

\begin{tabular}{lcc}
\hline Level of education & No. of farmers & Percentage \\
\hline Illiterate & 10 & 11.11 \\
Primary & 10 & 11.11 \\
secondary & 45 & 50.00 \\
Tertiary & 25 & 27.78 \\
Total & 90 & 100 \\
\hline
\end{tabular}

Table 4. Number of years the respondents have been living in Kiine area, Kenya

\begin{tabular}{lcc}
\hline No. of years & No. of farmers & Percentage \\
\hline 0 to 9 & 3 & 16.67 \\
10 to 19 & 7 & 38.89 \\
20 to 29 & 5 & 27.78 \\
30 to 39 & 2 & 11.11 \\
40 to 49 & 1 & 5.55 \\
50 to 59 & 0 & 0 \\
Total & 18 & 100 \\
\hline
\end{tabular}

Table 5. Climatic change in Kiine area, Kenya

\begin{tabular}{lcc}
\hline Response & $\begin{array}{c}\text { No. of } \\
\text { farmers }\end{array}$ & Percentage \\
\hline Climate has not always been as it is & 54 & 60 \\
The climate has changed & 36 & 40 \\
\hline
\end{tabular}

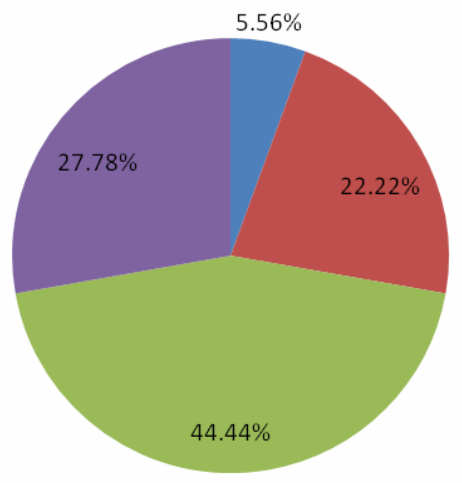

adry \& hot

cool \& wet

cool \& dry

not \& wet

Figure 2. Climate of Kiine area, Kenya

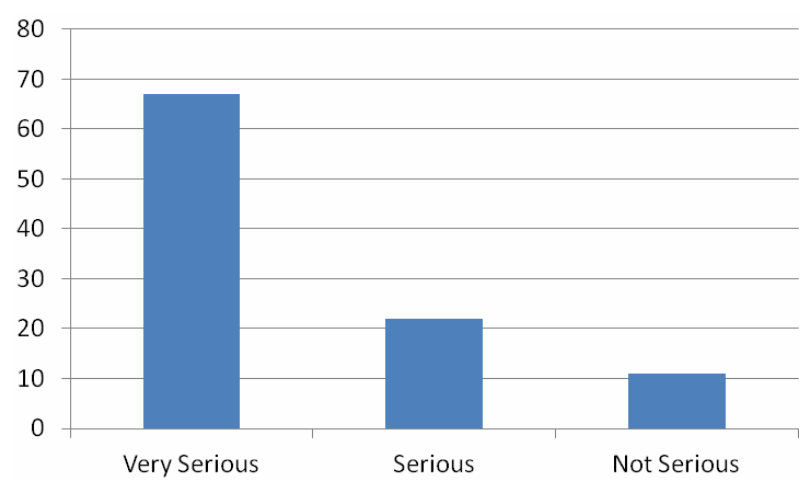

Figure 3. Impact of climate change in Kiine area, Kenya 
Table 6. Agroforestry practices

\begin{tabular}{|c|c|c|c|c|c|c|c|}
\hline Category & Category & 1 & 2 & 3 & 4 & 5 & Total \\
\hline \multirow[t]{2}{*}{ Planting trees and shrubs as windbreakers } & No. of farmers & 35 & 25 & 15 & 5 & 10 & 90 \\
\hline & $\%$ of farmers & 38.89 & 27.8 & 16.67 & 5.56 & 11.11 & 100 \\
\hline \multirow[t]{2}{*}{ Planting of riparian forest buffers } & No. of farmers & 30 & 30 & 10 & 10 & 10 & 90 \\
\hline & $\%$ of farmers & 33.33 & 33.3 & 11.11 & 11.11 & 11.11 & 100 \\
\hline \multirow[t]{2}{*}{ Silvopasture } & No. of farmers & 40 & 20 & 15 & 10 & 5 & 90 \\
\hline & $\%$ of farmers & 44.44 & 22.2 & 16.67 & 11.11 & 5.56 & 100 \\
\hline \multirow[t]{2}{*}{ Forest farming } & No. of farmers & 15 & 10 & 10 & 30 & 25 & 18 \\
\hline & $\%$ of farmers & 16.67 & 11.1 & 11.11 & 33.33 & 27.78 & 100 \\
\hline \multirow[t]{2}{*}{ Alley cropping } & No. of farmers & 4 & 4 & 1 & 4 & 5 & 18 \\
\hline & $\%$ of farmers & 22.22 & 22.2 & 5.56 & 22.22 & 27.78 & 100 \\
\hline \multirow[t]{2}{*}{ Boundary planting } & No. of farmers & 40 & 25 & 5 & 15 & 5 & 90 \\
\hline & $\%$ of farmers & 44.44 & 27.8 & 5.56 & 16.67 & 5.56 & 100 \\
\hline \multirow[t]{2}{*}{ Home garden } & No. of farmers & 7 & 6 & 1 & 2 & 2 & 18 \\
\hline & $\%$ of farmers & 38.89 & 33.3 & 5.56 & 11.11 & 11.11 & 100 \\
\hline \multirow[t]{2}{*}{ Planting of woodlots in moist region } & No. of farmers & 10 & 10 & 5 & 30 & 35 & 90 \\
\hline & $\%$ of farmers & 11.11 & 11.1 & 5.56 & 33.33 & 38.89 & 100 \\
\hline \multirow[t]{2}{*}{ Combination of trees with food crops } & No. of farmers & 30 & 35 & 5 & 15 & 5 & 90 \\
\hline & $\%$ of farmers & 33.33 & 38.9 & 5.56 & 16.67 & 5.56 & 100 \\
\hline
\end{tabular}

Note: 1. Strongly agree, 2. Agree, 3. Don't know, 4. Disagree, 5. Strongly disagree

Table 7 Agroforestry costs

\begin{tabular}{|c|c|c|c|c|c|c|c|}
\hline Agroforestry costs & Category & 1 & 2 & 3 & 4 & 5 & Total \\
\hline \multirow[t]{2}{*}{ Coaching on agroforestry be enhanced } & No. of farmers & 40 & 30 & 5 & 10 & 5 & 90 \\
\hline & $\%$ of farmers & 44.44 & 33.33 & 5.56 & 11.11 & 5.56 & 100 \\
\hline \multirow[t]{2}{*}{ Knowledge regarding agroforestry needed } & No. of farmers & 35 & 40 & 0 & 5 & 10 & 90 \\
\hline & $\%$ of farmers & 38.89 & 44.44 & 0.00 & 5.56 & 11.11 & 100 \\
\hline \multirow[t]{2}{*}{ Indigenous and exotic species needed } & No. of farmers & 45 & 35 & 0 & 5 & 5 & 90 \\
\hline & $\%$ of farmers & 50.00 & 38.89 & 0.00 & 5.56 & 5.56 & 100 \\
\hline \multirow[t]{2}{*}{ Resistance to agroforestry practices evident } & No. of farmers & 35 & 30 & 15 & 5 & 5 & 90 \\
\hline & $\%$ of farmers & 38.89 & 33.33 & 16.67 & 5.56 & 5.56 & 100 \\
\hline \multirow[t]{2}{*}{ Residents adapted to the current conditions } & No. of farmers & 10 & 10 & 5 & 30 & 35 & 90 \\
\hline & $\%$ of farmers & 11.11 & 11.11 & 5.56 & 33.33 & 38.89 & 100 \\
\hline
\end{tabular}

Note: 1 . Strongly agree, 2. Agree, 3. Don't know, 4. Disagree, 5. Strongly disagree

or not, $11.11 \%$ disagree while the remaining $5.56 \%$ strongly disagree that coaching of residents on agroforestry should be intensified. These encourage to an understanding that farmers in the study area are not well-informed on agroforestry farming implementations. The government and other stakeholders should thus create mechanisms to set appropriate coaching in this area. Even more, there was finding that when the respondents were inquired if the profound knowledge regarding agroforestry was required, a majority $(44.4 \%)$ stated that such knowledge is required, while only a few $(11.11 \%)$ stated that such knowledge is needed. Certainly, to invest in enhancing the capability of farmers is imperative. The respondents were also questioned if they needed both indigenous and exotic species of trees and crops. A majority (50\%) strongly agreed that they needed both indigenous and exotic trees and plants species while a minority (5.56\%) strongly disagree with this program. One of the interesting arguments about species needs and usage of agroforestry products has been brought up by Young (1987) as; "It is widely argued that the lengthy production period and the incidence of most of the costs at the time of establishment, create financial problems for farmers in adopting practices involving tree growing".

Other findings about agroforestry expenses are described circumstantially in Table 7 . The findings of this study reveal that there is discrepancy to agroforestry practices. This is supported by evidence at the time the respondents were questioned to asses the issue of discrepancy to agroforestry practices (Table 8).

Table 8. Discrepancy to agroforestry

\begin{tabular}{lccccc}
\hline Response & $\begin{array}{c}\text { Strongly } \\
\text { agree }\end{array}$ & Agree & Neutral & Disagree & $\begin{array}{c}\text { Strongly } \\
\text { disagree }\end{array}$ \\
\hline $\begin{array}{l}\text { No. of } \\
\text { people }\end{array}$ & 45 & 20 & 5 & 10 & 10 \\
Percentage & 50 & 22.23 & 5.55 & 11.11 & 11.11 \\
\hline
\end{tabular}


A majority (50\%) strongly agree that there was evidence of discrepancy to agroforestry praxes, while the minority $(11.11 \%)$ strongly disagree that such discrepancy in agroforestry praxes existed. This discrepancy can be emerged due to many factors such as capital, land tenure and tree ownership, social economic stratification, technology and the length of time for trees to be ready for harvest. On the question if the inhabitants had done an adaptation to the current conditions, $11.11 \%$ strongly agree, $11.11 \%$ agree, $5.56 \%$ were unsure, $33.33 \%$ disagree while the remaining $5.56 \%$ strongly disagree. This is a sign that the deforestation and environmental downgrade negatively affect inhabitants of Kiine and comprehensive efforts are needed to recover the neighborhood to its original conditions.

\section{Advantages of Agroforestry}

To discover the advantages of Agroforestry, the respondents were handed out with various positive effects of Agroforestry and requested to appraise them. Table 9 shows the responses of the farmers on advantages of agroforestry.

Table 9 shows that $50 \%$ of sample strongly agree that agroforestry can make the climate of the area better. This finding is reinforced by researches carried out by Torquebiau, (1994) which resumed that "Agroforestry can improve the resilience of agricultural production to current climate variability as well as long-term climate change through the use of trees for intensification, diversification and buffering of farming systems. For example, trees improve soil quality and fertility by contributing to water retention and by reducing water stress during low rainfall years. Trees can also reduce the impacts of weather extremes such as droughts or torrential rain".

Most of interviewee $(33.33 \%)$ strongly agree that agroforestry raises the production of wood for fuel, construction, craft, (Table 9). This is reinforced by Raintree (1991), who expresses that "agroforestry is an approach to agricultural production that can reduce the impacts of human activities and global climate change on the local environment. Agroforestry systems integrate commercial crop production into the natural forest environment, harnessing trees for a variety of benefits: improving soil structure, drainage, and nutrient levels; preserving biodiversity; increasing forage, firewood and other organic materials that are recycled and used as natural fertilizers; helping to regulate the water cycle; and providing shade".

On the request to express their feelings on the agroforestry and increased yield in food, craft, and medicinal crops, a majority 50\% agree, $33.33 \%$ strongly agree, $11.11 \%$ disagree while the remaining $5.56 \%$ strongly disagree. This is a sign that agroforestry raises the production of food, craft, and medicinal crops.

\section{Agroforestry contribution on subsistence raise}

The respondent was handed with a 5 point Likert scale which is used to appraise agroforestry contribution on the rise of their subsistence. The result is showed in Table 10. The research gave the following conclusions: on the statement that agroforestry is needed to enhance the market network between producers and consumers, $44.44 \%$ strongly agree, $27.77 \%$ agree, $5.56 \%$ were unsure, $11.11 \%$ disagree and the remaining $11.11 \%$ strongly disagree. On the question if the processing, handling, and marketing of products yielded by traditional agroforestry practices should be enhanced, $38.33 \%$ strongly agree, $33.33 \%$ agree, $11.11 \%$ were unsure, $5.56 \%$ disagree and the remaining $11.11 \%$ strongly disagree (Table 10). Table 10 also presents the result on the request to appraise the issue of escalated catchments areas for rivers, streams, wells due to agroforestry, the majority (55.56\%) strongly agree.

As described in Table 10, on the matter if nutrition and health of households should be enhanced through fruits based Agroforestry practices, a majority of the respondents $(27.77 \%)$ strongly agree. On the contrary, $11.11 \%$ of them strongly disagree with this approach. On the occasion that the respondents were inquired if improving, processing, handling, and marketing of products from agroforestry will boost adoption of Agroforestry practices, 33\% strongly agree, $38.88 \%$ agree, $11 \%$ were unsure, $5.56 \%$ disagree while the remaining $11 \% \%$ strongly disagree. On the question if putting in new germplasm for Agroforestry with a focus on trees with high economic benefit, 50\% strongly agree, $33 \% \%$ agree, $11 \%$ disagree and the remaining $5.56 \%$ strongly disagree. A majority of the respondents $(39 \%)$ strongly agree that adaptive capability of drylands farming to climate changes should be increased. Conversely, about $6 \%$ of the respondents strongly disagree with that thought.

Table 9. Advantages of agroforestry

\begin{tabular}{|c|c|c|c|c|c|c|c|}
\hline Advantages of agroforestry & Category & 1 & 2 & 3 & 4 & 5 & Total \\
\hline \multirow[t]{2}{*}{ Increased catchment for rivers, streams, wells } & No. of farmers & 50 & 20 & 5 & 10 & 5 & 90 \\
\hline & $\%$ of farmers & 55.56 & 22.22 & 5.56 & 11.11 & 5.56 & 100 \\
\hline \multirow[t]{2}{*}{ Improved climate } & No. of farmers & 45 & 25 & 5 & 5 & 10 & 90 \\
\hline & $\%$ of farmers & 50.00 & 27.78 & 5.56 & 5.56 & 11.11 & 100 \\
\hline \multirow[t]{2}{*}{ Increased wood } & No. of farmers & 30 & 30 & 5 & 15 & 10 & 90 \\
\hline & $\%$ of farmers & 33.33 & 33.33 & 5.56 & 16.67 & 11.11 & 100 \\
\hline \multirow[t]{2}{*}{ Increased food output, craft and medicinal crops } & No. of farmers & 30 & 45 & 0 & 10 & 5 & 18 \\
\hline & $\%$ of farmers & 33.33 & 50.00 & 0.00 & 11.11 & 5.56 & 100 \\
\hline \multirow[t]{2}{*}{ Improved livestock health and livestock products } & No. of farmers & 35 & 35 & 10 & 10 & 10 & 90 \\
\hline & $\%$ of farmers & 38.89 & 38.89 & 11.11 & 5.56 & 5.56 & 100 \\
\hline
\end{tabular}


Table 10. Methods of enhancing agroforestry

\begin{tabular}{|c|c|c|c|c|c|c|c|}
\hline Category & & 1 & 2 & 3 & 4 & 5 & Tota \\
\hline \multirow{2}{*}{$\begin{array}{l}\text { Enhancing the producers-consumers market network, value addition, and } \\
\text { processing of agroforestry products }\end{array}$} & Freq. & 8 & 5 & 1 & 2 & 2 & 18 \\
\hline & $\%$ & 44 & 28 & 6 & 11 & 11 & 100 \\
\hline \multirow{2}{*}{$\begin{array}{l}\text { Improving nutrition and health for households through integration of fruit tree } \\
\text { species }\end{array}$} & Freq. & 7 & 6 & 2 & 1 & 2 & 18 \\
\hline & $\%$ & 39 & 33 & 11 & 6 & 11 & 100 \\
\hline \multirow{2}{*}{$\begin{array}{l}\text { Improving the production, processing, handling, and marketing of agroforestry } \\
\text { products }\end{array}$} & Freq. & 5 & 5 & 3 & 3 & 2 & 18 \\
\hline & $\%$ & 28 & 28 & 17 & 17 & 11 & 100 \\
\hline \multirow[t]{2}{*}{ Enhancing forest farming } & Freq. & 6 & 7 & 2 & 1 & 2 & 18 \\
\hline & $\%$ & 33 & 39 & 11 & 6 & 11 & 100 \\
\hline \multirow[t]{2}{*}{ Introducing a new agroforestry germplasm } & Freq. & 9 & 6 & 0 & 2 & 1 & 18 \\
\hline & $\%$ & 50 & 33 & 0 & 11 & 6 & 100 \\
\hline \multirow[t]{2}{*}{ Enhancing adaptive capacity of dryland farming to climate change } & Freq. & 7 & 7 & 1 & 1 & 2 & 18 \\
\hline & $\%$ & 39 & 39 & 6 & 6 & 11 & 100 \\
\hline
\end{tabular}

The findings of this research result the following conclusion. Agroforestry practices can remarkably buttress the residents in dealing with undesirable impacts of climate change at the present while at the same time increasing tenacity against future impacts. The result of study done by other scholars support this conclusion, for example, Oram (1993) who stated that agroforestry practices make the farmers and their families able to diversify their farm practices and set up network to guarantee livelihood sustainability, like the availability of products to be traded in the market; Torquebiau (1994) who found that in Sumatra, for example, some people grow plants as a fount of food, diversified it with rubber plants in their fallow fields; while in Borneo, some people cultivate rattan in rice fields during the last rice season and the rattan which is a very aggressive vine will use any neighboring trees as supports. He added further that rattan is a very profitable crop and can be harvested after 8-10 years.

\section{REFERENCES}

Agarwal B. 1997. Gender, environment, and rural poverty interlinks regional variations and temporal shifts in rural India, 1971-1991. World Dev 25 (1): 23-52.

Agroforestry Research Trust. 2010. Heartland Institute 2009 Internationa Conference on Climate Change, March 8-10, 2009, New York.

Brocklesby MA, Hinshelwood E. 2001. Poverty and the environment: What the poor say: An assessment of poverty-environment linkages in participatory poverty assessments. Centre for Development Studies, University of Wales, Swansea, UK,

CIDP. 2013. Kirinyaga County First County Integrated Development Plan 2013-2017. Office of the Governor, Kirinyaga County, Kutus, Kenya

Cleaver, K. 1997) Rural development strategies for poverty reduction and environmental protection in Sub-Saharan Africa. World Bank, Washington D.C.

Cochran WG. 1963. Sampling Techniques. 2nd ed. John Wiley and Sons, Inc., New York.

DFID, EC, UNDP, World Bank. 2002. Linking Poverty Reduction and Environmental Management Policy Challenges and Opportunities. Department for International Development, United Kingdom (DFID), Directorate General for Development, European Commission (EC), United Nations Development Programme (UNDP), The World Bank, July 2002.
Ezzati M, Kammen DM. 2001. Quantifying the effects of exposure to indoor air pollution from biomass combustion on acute respiratory infections in developing countries. Environ Health Perspect 109 (5): 481-488.

IPCC. 1990. The Science of Climate Change. Key Findings of IPCC Working Group 1. Intergovernmental Panel on Climate Change, Geneva, Switzerland.

IPCC. 2007. Climate Change: Impacts, Vulnerabilities and Adaptation in Developing Countries. Intergovernmental Panel on Climate Change. Intergovernmental Panel on Climate Change, Geneva, Switzerland.

ICRAF [World Agroforestry Centre]. 2013. Strategy 2013-2022: Transforming lives and landscapes with trees. World Agroforestry Centre, Nairobi.

KCTIP. 2014. Kirinyaga County Transition Implementation Plan. Office of the Governor, Kirinyaga County, Kutus, Kenya

KIHBS. 2005/2006. Kenya Integrated Household Budget Survey 20052006. Kenya National Bureau of Statistics (KNBS), Nairobi, Kenya

Kombo DK, Tromp DL. 2006. Proposal and Thesis Writing. An Introduction. Paulines Publications, Nairobi

Kothari CR. 2004. Research Methodology: Methods and Techniques. 2nd ed. New Age International Ltd., New Delhi.

KPHC. 2009. 2009 Kenya Population and Housing Census Reports. Kenya National Bureau of Statistics (KNBS), Nairobi, Kenya

Kwesiga F, Akinnifesi FK, Mafongoya PL, McDermott MH, Agumya A. 2003. Agroforestry research and development in southern Africa during the 1990s: Review and challenges ahead. Agrofor Syst 59: 173-186.

Mugenda A, Mugenda O. 2003. Research Methods; Quantitative and Qualitative Approaches. African Centre for Technology Studies, Nairobi.

Oram P. 1993. Global Perspective on Population, Resources and Agricultural. Proceedings of the 7 Australian Agronomy Conference, Adelaide, 1993. Australian Society of Agronomy, Carlton, Australia.

Pearce F. 2003. Land of the midnight sums. New Scientist 177: 2379.

Pierrehumbert RT. 2004. Warming the World. Nature 432: 677.

Raintree JB. 1991. Socio-economic attributes of trees and tree planting practices. Community Forestry Note 9. FAO, Rome.

Sanchez P.A. 2000. Linking climate change research with food security and poverty reduction in the tropics. Agric Ecosyst Environ 82: 371383.

Torquebiau E. 1994. Agroforestry Research for Integrated Land Use: An Introduction to the Concept of Agroforestry. ICRAF, Nairobi, Kenya.

UN. 1995. World Summit for Social Development, Copenhagen, Denmark, 6-2 March 1995.

UNDP. 2000. Human Development Report 2000: Human Rights and Human Development. United Nations Development Programme \& Oxford University Press. New York.

Young A. 1987. The Potential of Agroforestry as a Practical Means of Sustaining Soil Fertility. ICRAF, Nairobi, Kenya. 